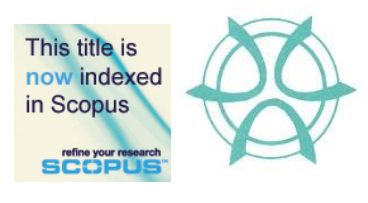

PLANNING MALAYSIA:

Journal of the Malaysian Institute of Planners

SPECIAL ISSUE V (2016), Page 89 - 100

\title{
INCORPORATING WALKING IN TRAVEL TO WORK: THE MEANING OF COMMUTING FOR KUALA LUMPUR COMMUNITY
}

\author{
Mastura Adam $^{1}$ \& Ahmed Abubakar ${ }^{2}$ \\ ${ }^{1,2}$ Centre for Sustainable Urban Planning \& Real Estate \\ Faculty of Built Environment, \\ UNIVERSITY OF MALAYA
}

\begin{abstract}
Progressive increase in the influx of privately owned vehicles and a decrease in the modal share of public transport over the years become a city-based phenomenon. Over-dependence on cars encouraged a sedentary lifestyle, an obesity epidemic, social exclusion and increased carbon footprint. Deficiencies in urban planning have created a spatial separation between employment centres and residential areas. The research focused on investigating how people construct the meaning attributed to commuting mode of travel to work. Using multiple embedded case study research approach, this research focuses on 19 semistructured interviews with employees from two neighbouring but contrasting case study areas of Kuala Lumpur. Synthesis of the employees' experiences on their travel behaviour exposed replication logic on the way they perceived walking as part of the transportation mode of travelling to work. The implicit understanding of the walking to work includes; definition of walking to work by the communities, specific walking stages and its' characteristic during am-pm rush hours, the travel pattern and modes of transportation from the origin point (home) to the office, and the understanding of walking benefits to their economy, environment, health and social. These results provide possibility of understanding the needs of people and to promote walking to work as part of transportation mode for commuting in order to overcome the current urban challenges.
\end{abstract}

Keyword: Travel to work, walking experience, pedestrian environment, resilience, transformation, sustainable transportation 
Mastura Adam \& Ahmed Abubakar

Incorporating Walking in Travel to Work: The Meaning of Commuting for Kuala Lumpur Community

\section{INTRODUCTION}

Urban mobility remains a challenge, which requires a resilient approach through the incorporation of the social dimension within the contemporary planning practices (Wikström, 2013). To this end, a pedestrian point of view is critical to influencing the transformation of the environment through the adaptation of resilient based practices. The benefit of walking as the first mode of transportation makes it the most sustainable form to date (Grava, 2003). Walking when compared with other forms of exercises appeared simpler, freer, cheaper and therefore prevalent way of moving from place to place. Morris and Hardman (1997) described walking as the best form of exercise. Several pieces of evidence advanced equate positive health status with active living. Thus, a committee of experts expressed their concern, that the values of physical activity reiterated in Australia exist for more than a decade, yet, participation remains static if not declining because of issues related to human's perception and conveniences. Thus, researchers from different background discipline highlighted on the needs to encourage walking as a means of transportation (Department of Health, 2004; Lee and Moudon, 2006).

Deficiency in urban planning, scarcity and high cost of land and landed properties translate into the spatial separation between people and their place of work (Bauman, 1999). Such land uses are inadequately coordinated with various modes of transportation resulting to the high influx of privately owned vehicle dominating the movement space for daily commuting into the city centre. This phenomenon causes in long hours and inefficient commuting to work due to severe traffic congestion mainly during rush hours. Issues related to environmental outcomes into sustainable transportation dominated the focus of research attention. Thus, the benefit of walking in the transformation of the urban environment, economic and social sustainability has been established adequately in literature in order to make changes in the society's perspective towards walking as part of a transportation mode (Adam, 2013; Giles-Corti, Foster, Shilton, \& Falconer, 2010; Lee and Moudon, 2006).

What is lacking, however, is the adoption of walking habit because it has not been viewed, and was not seen as a development with high fruition coefficient to the societies. Insufficient literature to understand the walking attitude to the place of work coupled with the popular misconception that walking is not a transportation option reinforced the indication that there are knowledge gaps in this respect. To bridge this gap, a research focus on a resilient approach cognizant of the pedestrian points of view is imperative. Thus, the study seeks to investigate how people construct the meaning of commuting in their built environment and how walking could be incorporated as part of travel to work.

Knowledge of walking attitude is expected to give insight into useful strategies for incorporating walking to work attitude, not only in Kuala Lumpur (KL) but other places anticipating similar constraints for a sustainable 
transportation. In this research, the employees' have been selected as a unit of analysis, because they are the majority group that was most likely to seek accommodation outside Kuala Lumpur city centre. Thus, employees' need to make long distance trips every day.

\section{LITERATURE REVIEW}

Walkability in pedestrian environments is the extent to which the built environment supports and encourages walking by providing for pedestrian comfort and safety. The capacity to move about on foot in a given space connotes walk-ability (Southworth, 2007). Walkability in the pedestrian environment improved with the inclusion of the following: protection, comfort, and safety ( Transport for London \& Central London Partnership, 2004). Walking and walkability are believed to have a major impact on community life, which mostly happens on the streets (Litman, 2011). This topic is widely discussed among the scholars on its benefit and resilience to health, the environment, economy, and social inclusion.

Resilience to Health: Many researchers like to demonstrate a positive relationship between positive health status and active life. Heart diseases and even cancer can be linked to physical inactivity (British Heart Foundation, 2001; Chief Medical Officer, 2004). Consequently, physical inactivity heightened by privately owned vehicles has seen the dawn of our times. Obesity is the order of the day due global rise of inactivity and overeating (Kopelman, 2000).

Environmental resilience: Practically, however, sustainability benefits are relegated to the background. Carbon neutral manner of transportation with all the positive selling point is fast becoming a thing of the past and of those who cannot afford luxurious gratifications accorded by "mechanical civilization". Private vehicles become the easy targets. Walking burns no fossil fuel (Tolley, 2003). Accordingly, mix-mode of transportation promises a better reward for a sustainable future (Department of Health, 2004). Yet, currently, mix-mode transportation is an exception rather than the rule.

Economic Sustainability: Advances made towards attaining a community economic goal include; increase in economic productivity, employment, business activities and investments and are collectively referred to as economic development. Again, it has been established that customers usually walk. Those customers that walk spend more than those that drive (Litman, 2009). Walking promotes low dependency on fuel and its associated costs (British Heart Foundation, 2001).

Social Inclusion: Social benefit of walking is apparent in a neighbourhood community of people with different social class and background. Quality relationship or "community cohesion" among people increases with positive interactions. These "social capitals" rely on the quality pedestrian travel path, such as sidewalks and routes. Social interactions and is necessary for 
Mastura Adam \& Ahmed Abubakar

Incorporating Walking in Travel to Work: The Meaning of Commuting for Kuala Lumpur Community

virtually every activity that requires people to venture outside of their homes. City centres across the globe are opting for a sustainable and resilient transformation approach, through sustainable urban transportation network (Adam, 2013).

\section{RESEARCH METHODOLOGY}

This study utilizes multiple embedded case study approach (Yin, 2009), which draws on unknowable ontological reality perceived differently by individuals and therefore with deductive epistemology (Sexton, 2003). A case study approach is deemed appropriate to answer the question of why and how (Yin, 2009). In this case, why and how pedestrians choose to incorporate walking to work attitude and how the employees construct the meaning of their working to work, in the research settings. The knowledge of the way in which the study respondents constructed their world was obtained from empirical inquiries through an indepth semi-structured interview based on their understanding of a real phenomenon being investigated.

Selection of respondents: Judgmental (snowball) sampling that allows the researcher to select respondents based on predetermined criteria in line with the research objectives (Patton, 2002). Sarantakos (2005) emphasises the relevance of purposive sampling in qualitative research, and the need for obtaining representativeness based on strategies that ensure samples match the population characteristics. A total of 19 semi-structured interviews were conducted with employees working in the two case study areas in Kuala Lumpur (KL). The respondents were asked on their general background that includes; their place of origin (home); the travel pattern from the place of origin in the first mile and their final transit to the workplace in KL city centre known as the last mile; The modes of transportation that they used to go to work daily, their perception of walking as a means of transportation, their understanding on the meaning of walking to work and the benefits of walking for health, social, environment and economy.

The criteria for the selection of the respondents are: being an adult employee, walking from the final transit station to the office or from parking spaces (in surrounding areas) to the offices, walking to work during peak hours (AM and PM), and a wide range of job position to get a holistic opinion (senior and junior executives, maintenance personnel and office secretaries). For the purpose of anonymity and ease of analysis, ten (10) respondents (R) works in Office A from Central Business District (CBD) in Site A and nine (9) respondents works in Office B from Kuala Lumpur City Centre (KLCC) in Site B, were coded as Site A (SA) and Site B (SB) respectively. R1-SA to R10-SA and R1-SB to R9$\mathrm{SB}$ represents the respondent range in SA and SB respectively.

The study area: Two case study areas were chosen as samples, to represent the phenomena in the real life context of people walking in the existing pedestrian 


\section{PLANNING MALAYSIA \\ Sustainable Urban Development}

environment. The areas are known as Central Business District (CBD) namely as Case Study 1 (CS1) and Kuala Lumpur City Centre (KLCC) as Case Study 2 (CS2); both are located in the city centre of KL. CS1 is a prominent employment district; it was formerly a part of the CBD before World War II. Rapid development during the 20th century has meant that these districts have experienced unplanned development with a disorganised mixture of old and new development. In the contrary, CS2 was developed during the era of globalisation and was envisioned as an urban masterpiece for KL.

\section{RESULT AND FINDINGS}

In order to extract meaning from the interviews, content analysis is used to analyse the transcribed interview data. Content analysis of the data aimed at establishing a pattern of responses (Krippendorff, 2012). The assigned coding of the interview data for SA and SB is based on themes. The findings are organised using NVivo 10 software under a tree node structure in three major themes (parent node, child node and leaf node). Implicit understanding of Walking to Work (ImU) theme exposed thick and rich information on how people assign meaning to walking to work. The concepts of implicit understanding of walking to work were established within each case study area as shown in Figure 1.

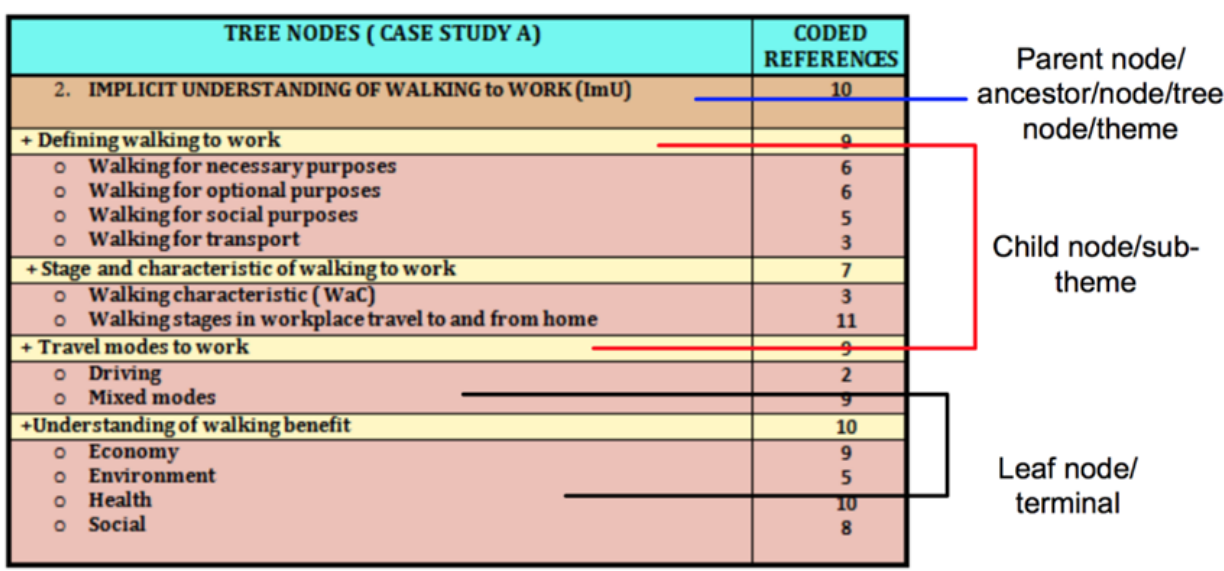

Figure 1: Findings from the implicit understanding of walking to work emerged from Case Study A, as well as in Case Study B respectively

In the searching for within-group similarities and inter-group a difference in pattern, replication logic was employed (Yin, 2009). Respondents were asked about how to define walking to work based on their daily routine and experience. The discussion centred on generating the understanding through the definition of walking to work as understood by the respondents. 
Mastura Adam \& Ahmed Abubakar

Incorporating Walking in Travel to Work: The Meaning of Commuting for Kuala Lumpur Community

The majority of the respondents (95\%) for both case study areas strongly stated their reason for walking to work in this area as a necessity whereas walking during the lunch break as walking for social purposes and optional. The result of the cross-case synthesis reveals that although the definition of walking to work depends on the individual's perception, similarities exist between pedestrian perceptions in CS1 and CS2 as shown in Table 1.

Table 1: Synthesis on the definition of walking to work for Case Study 1 and Case Study 2

\begin{tabular}{|c|c|}
\hline 1 & Са \\
\hline $\begin{array}{l}\text { - Walking to work is considered as a } \\
\text { - } \\
\text { Testination directed. } \\
\text { functional because there is a focus on the } \\
\text { origin, the destination and the time gap } \\
\text { between the two. } \\
\text { Walking from station to office is } \\
\text { described as a straightforward path } \\
\text { because there is no room for distractions } \\
\text { Walking is the most appropriate mode of } \\
\text { transportation for short-distance trips as } \\
\text { an alternative to automobiles. } \\
\text { Walking for a lunch break is considered } \\
\text { a regular activity for the purpose of } \\
\text { socializing with companions. }\end{array}$ & $\begin{array}{l}\text { - Walking to work as a physical activity } \\
\text { that serves the functional purposes } \\
\text { categorized as necessary. } \\
\text { Walking to work means walking to } \\
\text { transit. } \\
\text { Walking with a very specific and set } \\
\text { target for the purpose of going to work. } \\
\text { Body and mind focused on reaching the } \\
\text { destination, i.e. home or work. } \\
\text { Walking for lunch break is considered as } \\
\text { routine practice for the employee } \\
\text { Walking for lunch break is } \\
\text { acknowledged as being for the purposes } \\
\text { of socializing }\end{array}$ \\
\hline
\end{tabular}

The child node 'travelling mode to work' refers to the method or means an individual takes to reach the office within CS1 (Office A) and CS2 (Office B) from their place of origin. For CS1 and CS2, only a few respondents said they drove to the city centre every day, $95 \%$ of the respondents mentioned travelling to work using a mixture of transportation modes to commute to the workplace in the city centre (a combination of walking, LRT, buses, cars, etc.). The reason for respondents to incorporate walking as part of their travel modes is to avoid severe traffic congestion, proximity to public transport facilities and awareness of the benefit of walking. Points of origin identified for the respondents from both case studies are many, but all live outside the city-centre, in the KL metropolitan area, or in the adjacent states as shown in Figure 2. 
PLANNING MALAYSIA

Sustainable Urban Development

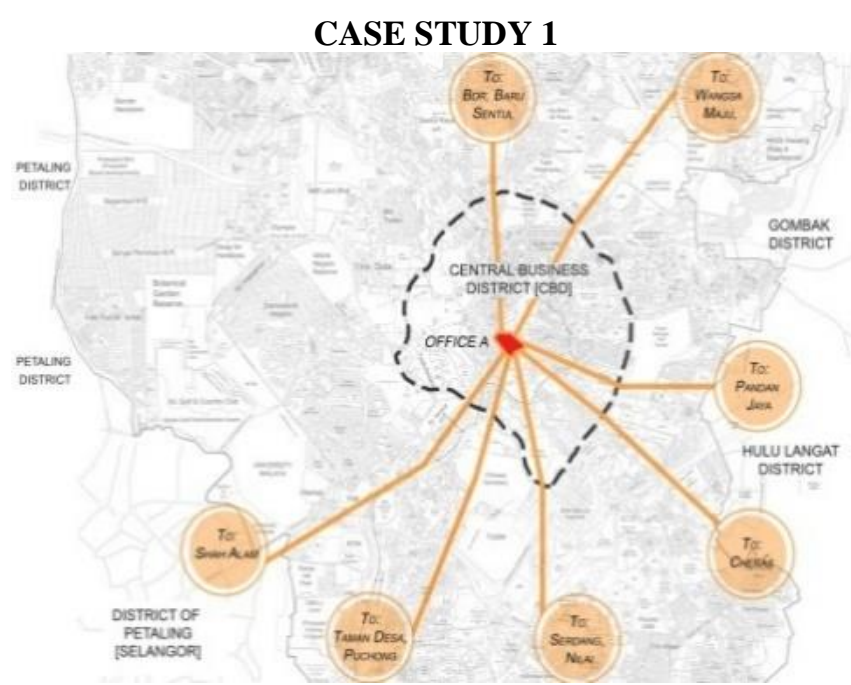

CASE STUDY 2

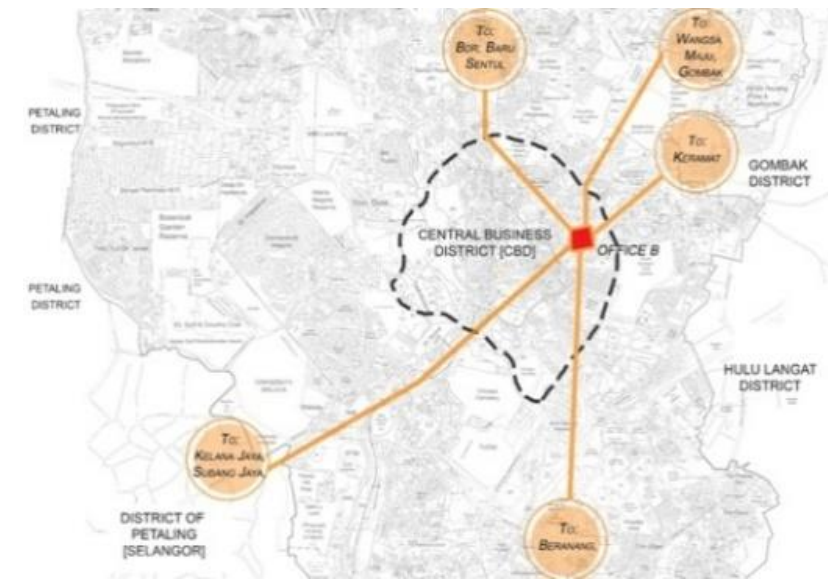

Figure 2: Synthesis on the Travel Pattern to Work for the Case Study 1 and 2

Walking emerges as the main mode of transport from the final transit station as they arrive in the city centre to their destination in Office A (CS1) and Office B (CS2). Respondents comment on incorporating walking habit in their travel to work for their health and agreed that it is able to promote healthy mental state and improves the quality of life. "... It's a health concern, you're reducing your cholesterol, and you're sharing this road walking from point $A$ to point $B$, which means I'm familiarizing with the environments and surroundings which make it easy to relax." (R4-SA). Respondent R3-SB expressed his frustration at those whom he considered as ignorant of the benefits of walking. He said: "Yes, definitely people don't want to take it seriously because they have no idea of the immediate effect on their health in a positive manner". 
Mastura Adam \& Ahmed Abubakar

Incorporating Walking in Travel to Work: The Meaning of Commuting for Kuala Lumpur Community

When asked about the benefit of walking economy wise (all the 10 respondents [100\%]) from CS1 agreed that walking to work is a part of multimodal transport, or walking, in general, allows them to be more economical in their expenses. Whereas $80 \%$ respondents in CS2 responded in a positive manner that walking helps save money that would have otherwise been spent on monthly travelling expenses. The car users and those who walked or used multi-mode transportation calculated their expenses; the results showed that those who used cars as a mode of transportation spent more on fuel, maintenance and parking on a weekly basis as compared to those who incorporated walking in mixed transportation mode. Respondent (R2-SA) calculated the cost per week as follows: "If I drive the car to work, in a week I spend, [calculating], over RM150. So I save around RM25 to RM40 per week. I buy fuel at around RM30 per week (on a good week when I have nowhere else to go), parking RM50 and car maintenance maybe around RM100 per month" (R2-SA).

Only about $50 \%$ of the respondents in CS1 took the impact of the automobile as a serious matter, which needs to be addressed, particularly, in relation to the issue of traffic congestion and emissions within the city. Meanwhile, in CS2, 90\% of the respondents (8 out of 9) mentioned that they are fully aware of the negative impact of carbon emissions, which are caused mainly by automobiles, on the environment. One of the respondents in CS2 displayed his genuine understanding of the greenhouse effect: "If I take [drive] the car, do you know how much I alone pollute the earth with the $\mathrm{CO}$ and $\mathrm{CO}_{2}$ emissions? When we talk about walking, that means my car is not moving. If my car is not moving, what does it mean in terms of the environment? It means I saved my share of the environment by not adding to the greenhouse effect that deteriorates the world. Whenever I save fuel, I am not polluting the world. By walking I can save the world" (R1-SB).

Respondents were asked about the social benefit of walking. Most of the respondents (9 out of 10 [95\%]) from CS1 felt that socializing during transportation, especially walking, is important to enliven the surroundings and make the trip a worthwhile one. Nine respondents in CS2 described a positive correlation between walking and social life as tabulated in Table 1 and 2 .

Table 2: The replication logic of pedestrian environments' condition and needs for both case study areas based on synthesis of the walking stages and its characteristics

\begin{tabular}{lll}
\hline $\begin{array}{l}\text { The Stage and Characteristics of } \\
\text { Walking to Work }\end{array}$ & $\begin{array}{l}\text { Replication } \\
\text { Environments Condition and Needs }\end{array}$ \\
\hline 17 out of $19(89 \%)$ reported their walking & - Straight forward and direct routes \\
stage during the AM rush hour as walking & $\begin{array}{l}\text { - Transit choices closer to the workplace } \\
\text { from the final transit point in the city centre }\end{array}$ & $\begin{array}{l}\text { - Efficient public transport network and } \\
\text { services }\end{array}$ \\
in the workplace. The walking & $\begin{array}{l}\text { - Safety and security along the routes } \\
\text { characterised as: }\end{array}$ & $\begin{array}{l}\text { - Minimal obstacles on the sidewalks, } \\
\text { - Common to walk alone }\end{array}$ \\
- Fast walking pace &
\end{tabular}


PLANNING MALAYSIA

Sustainable Urban Development

\begin{tabular}{|c|c|}
\hline nd are pressured by time. & $\begin{array}{l}\text { - Efficient pedestrian infrastructure and } \\
\text { facilities. }\end{array}$ \\
\hline $\begin{array}{l}17 \text { out of } 19(89 \%) \text { reported their walking } \\
\text { stage during the PM rush hour as walking } \\
\text { from the workplace to the transit point for } \\
\text { the home. The walking characterised as: } \\
\text { - Walk at a leisurely pace, } \\
\text { - Body and mind are more relaxed about } \\
\text { time } \\
\text { - Have more time to observe the } \\
\text { surroundings }\end{array}$ & $\begin{array}{l}\text { - Safety and security along the routes } \\
\text { - Looking for more varied uses along the } \\
\text { routes such as cafes, retail outlets, artworks } \\
\text { - Attractiveness and details of sidewalks and } \\
\text { route design } \\
\text { - Adequate street furniture and lighting }\end{array}$ \\
\hline $\begin{array}{l}18 \text { out of } 19(94 \%) \text { reported walking from } \\
\text { the workplace to the eatery during the } \\
\text { afternoon break and characterised as: } \\
\text { - Fast walking pace } \\
\text { - Best time to rejuvenate and refresh the } \\
\text { mind and body, } \\
\text { - socializing while walking with } \\
\text { colleagues }\end{array}$ & $\begin{array}{l}\text { - Looking for more varied uses along the } \\
\text { routes such as cafes, food outlets, and retail } \\
\text { outlets } \\
\text { - focus on the destination to reduce travel time } \\
\text { - straight forward and direct routes } \\
\text { - safety and security along the routes } \\
\text { - minimal obstacles on the sidewalks } \\
\text { - efficient pedestrian infra and facilities }\end{array}$ \\
\hline $\begin{array}{l}18 \text { out of } 19(94 \%) \text { reported walking from } \\
\text { eatery to workplace during the afternoon } \\
\text { break and characterised as: } \\
\text { - Fast walking pace } \\
\text { - walking with colleagues }\end{array}$ & $\begin{array}{l}\text { - straight forward and direct routes } \\
\text { - safety and security along the routes } \\
\text { - minimal obstacles on the sidewalks } \\
\text { - efficient pedestrian infra and facilities }\end{array}$ \\
\hline
\end{tabular}

Walking stage and its characteristics are influenced by the type of environment required for walking from the final transit point to the workplace. It is also depends on the time of walking (am-pm rush hour) and the pedestrian environment conditions that support their needs as shown in Table 2 above.

Apart from the time, the respondents also giving their feedback on the type of travel modes practiced in CS1 and CS2. This is including the walking stages performed by them to and from home as in the first mile and the final transit at their workplace in KL city centre (the last mile). The results are explained in five categories as follows:

Category 1: Driving from home straight to the office car park $\rightarrow$ then walking from the car park to the office workplace. $10.6 \%$ respondents engaged fully in the car driving with minimum walking.

Category 2: Driving from home to the nearest LRT $\rightarrow$ then commuting from the LRT to the next LRT near the office area $\rightarrow$ then walking to the workplace from the transit station. $21 \%$ respondents incorporated walking with this mixed mode travel pattern.

Category 3: Walking from home to the nearest bus stop $\rightarrow$ then ride the bus to the nearest LRT station or train commuter $\rightarrow$ then commute with LRT or train commuter to the nearest station at the office area $\rightarrow$ then walking to their 
Mastura Adam \& Ahmed Abubakar

Incorporating Walking in Travel to Work: The Meaning of Commuting for Kuala Lumpur Community

office workplace. $5.3 \%$ respondents incorporated walking with this mixed mode travel pattern.

Category 4: Walking from home to the nearest bus stop, $\rightarrow$ then ride the bus to the bus stop near the office area, $\rightarrow$ then walking to the office workplace. $15.8 \%$ respondents incorporated walking with mixed mode travel pattern.

Category 5: Walking from home to the nearest LRT station, $\rightarrow$ then commute with the LRT to the LRT station near the office area, $\rightarrow$ then walking to the office workplace. $42 \%$ respondents incorporated walking with this mixed mode travel pattern.

Category 2, 3, 4 and 5 also indicated that those who have greater proximity to the public transport from their home to the workplace in the city centre utilizes the facilities. Whereas those who do not will depend on their cars as a means of transportation to travel to work as in category 1 .

\section{DISCUSSION}

The research set out to investigate how people construct the meaning of commuting in their built environment and how walking could be incorporated as a mode of transportation to the place of work. Although understanding the pedestrian perception is important, various factors influence the pedestrian sensitivity to walking to work. The focus is placed on getting an insight into the actual meaning of walking to work.

Firstly, understanding and meaning respondents attached to walking as a viable tool for mobility can be categorized into four emerging purpose; i) walking for necessary purposes; ii) optional purposes; iii) walking for social purposes, and iv) walking for transportation. Thus, the majority of the respondents considered walking as part of transportation mode a necessity. Respondents that considered walking as optional or for socializing attached the meaning to walking during the lunch break. This finding reinforced the assertion that perceptions and experiences have an influence in making decisions to opt for walking as part of a transportation mode, including public transportation, instead of driving private vehicles ( Transport for London \& Central London Partnership, 2004).

Secondly, understanding of the benefit of walking by the respondents emerged in four categories: walking for health, economic, environmental and social benefits. Once the benefit of walking is understood, people could develop a positive mind-set that incorporates walking in their daily travel to work. Thus, there is a need to embark on improving awareness of the positive benefits of walking and the modification of the pedestrian environment.

Thirdly, travel mode to work appeared in two ways; driving mode and mixed mode of transportation by the majority of people, who worked in the city centre of KL. This scenario revealed the fact that people need to stay connected even though their travel behaviour emerged complex. Apparently, the current scenario may appear normal, however, in reality, it is not complying with 
PLANNING MALAYSIA

Sustainable Urban Development

sustainable travelling. Interpretation of Category 2, 3, 4 and 5 shows the possibility of incorporating walking as part of mixed modes of transportation to the workplace. Category 1 , however, is purely driving mode, which is not recommended for sustainable transportation for the community.

Fourthly, walking is only effective where the mixed mode of transportation is involved as against the driving mode. The effectiveness can be translated into the economic, social, environmental and above all the health benefits for workers. Any policy on transportation drafted needs to encourage the community to opt for a mixed mode for the immediate and long-term benefit. An integrated approach that involves various disciplines could be a step change in envisioning and advocating for a quality pedestrian environment that encourages people to incorporate walking in the city (Litman, 2011).

This research also revealed that walking characteristics of workers are determined to a large extent by travel time, characteristic of walking condition and needs. Thus, there is a need to improve physical facilities to support walking and remove barriers that may constitute obstacles and increase time consumption.

\section{SUMMARY}

The study reveals that users react to the reality that surrounds them, and that walking is associated with a reduction in car dependency, but sometimes with a negative social status symbol. Synthesis of the travel behaviour from a place of residence of the respondents in the metropolitan periphery to the workplace in the city centre exposed replication logic of the way people travel to work in the city of Kuala Lumpur. The research has explored on the understanding of the meaning of walking to work and its associated benefit to health, economy, environment and health. Ultimately, choices of travel mode are depending on proximity and availability of mix-mode choices. Insight from the perspective of the respondents revealed how employees construct meaning to their traveling modes to answer the research objectives. Respondents have displayed a resilient path through adapting to the current problems of travelling to work in the city of Kuala Lumpur. A holistic understanding of travel behaviour, thus, provides an insight into the transformation towards a sustainable travelling to work conceptually. These findings present an invitation to the stakeholders and researchers for further research in the area of advocating for a mixed mode of transportation for the community.

\section{ACKNOWLEDGEMENTS}

The study is supported with the sponsorship of University Malaya (SLAB Scheme) and Ministry of Higher Education Malaysia (MoHE) (SLAI Scheme) for Ph.D. study in the University of Salford, Greater Manchester, United Kingdom. 
Mastura Adam \& Ahmed Abubakar

Incorporating Walking in Travel to Work: The Meaning of Commuting for Kuala Lumpur Community

\section{REFERENCES}

Adam, M. (2013). An Exploration of the Employee's Perception of Walking: Enhancing the Walking Experience in Kuala Lumpur. (Ph.D.), University of Salford, UK, An unpublished Ph.D. Thesis.

Bauman, A., Smith, B., Stoker, L., Bellew, B. \& Booth, M. (1999). Geographical influences upon physical activity participation: evidence of a "coastal effect". Australia and New Zealand Journal of Public Health, 23(3), 322-324.

British Heart Foundation. (2001). Physical Activity and Your Heart: Health Information Series 1. [Retrieved 2014 Dec 23]. Available from: /http://www.bhf.org.uk/ publications/uploaded/bhf_his01_physical_activity.pdf,S.

Chief Medical Officer (2004). At least five a week: evidence on the impact of physical activity and its relationship to health. London: Department of Health.

Department of Health (2004). Choosing health: making healthy choices easier. London: Stationery Office.

Giles-Corti, B., Foster, S., Shilton, T. \& Falconer, R. (2010). The co-benefits for health of investing in active transportation. New South Wales Public Health Bulletin, 21(6), $122-127$

Grava, S. (2003). Urban Transportation Systems: Choice for communities. New York, McGraw-Hill.

Kopelman P. G. (2000). Obesity as a medical problem. Nature, 404(6778), 635-643.

Krippendorff, K. (2012). Content Analysis: An Introduction to Its Methodology. London: Sage.

Lee, C. \& Moudon, A. V. (2006). Correlates of walking for transportation or recreation purposes. Journal of Physical Activity \& Health, 3, S77.

Litman, T. (2011). How Land Use Factors affect Travel Behavior. Victoria Transport Policy Institute. Retrieved from http://www.vtpi.org viewed 12/05/11.

Litman, T. A. (2009). Economic value of walkability. Transportation Research Record: Journal of the Transportation Research Board, 1828, 3-11.

Morris, J. \& Hardman, A. (1997). Walking to health. Sports Med, 23, 306-332.

Patton, M. Q. (2002). Two decades of developments in qualitative inquiry a personal, experiential perspective. Qualitative Social Work, 1(3), 261-283.

Sarantakos, S. (2005). Social Research. South Melbourne: Palgrave Macmillan.

Sexton, M. (2003). A supple approach to exposing and challenging assumptions and path dependencies in research. Paper presented at the 3rd International Postgraduate Research Conference, April, Lisbon, Portugal.

Southworth, M. (2007). Designing the walkable city. Journal of Urban Planning and Development, 131(4), 246-257.

Tolley, R. (2003). Providing for Pedestrians: Principles and Guidelines Access To Destinations and Urban Spaces. Department of Infrastructure, Victoria, Australia.

Transport for London \& Central London Partnership (2004). Towards a fine city for people. Retrieved from https://issuu.com/gehlarchitects/docs/ issuu_270_london_pspl_2004.

Wikström, A. (2013). The Challenge of Change: Planning for Social Urban Resilience: An Analysis of Contemporary Planning Aims and Practices. Master's Thesis, Stockholm Uiversity.

Yin, R. K. (2009). Case study research: design \& methods. Thousand Oaks: Sage. 